\title{
Estrategias de comunicación periodística para publicar en Redes Sociales desde la prensa local: Plan de Acción de Grupo Joly
}

\author{
Magdalena Trillo-Domínguez \\ Universidad de Granada \\ mtrillo@ugr.es \\ http://orcid.org/0000-0001-9505-1203
}

\author{
Jesús Ollero \\ EUSA, Universidad de Sevilla \\ jollero@grupojoly.com \\ https://www.twitter.com/ollerista
}

\section{Local press strategies of journalistic communication for Social Media publishing: Grupo Joly Action Plan}

\begin{abstract}
RESUMEN
La interacción de la prensa con los lectores se ha limitado históricamente a publicar diariamente una selección de cartas al director. Con la expansión de las redes sociales, con más fuerza e impacto transformador que la propia web, los diarios empiezan a asumir el desafío de publicar y gestionar los contenidos aprovechando las características de los nuevos soportes y sus potencialidades. Las empresas, en un primer momento, se han debatido entre ignorar el nuevo ecosistema de medios y adaptarse replicando contenidos sin más. Las múltiples crisis que han sacudido al sector han obligado, sin embargo, a activar planes específicos de formación, implementar desarrollos tecnológicos acordes a las necesidades y responder a las exigencias de los usuarios con un objetivo ineludible de supervivencia. Grupo Joly, empresa periodística de referencia en Andalucía, es un ejemplo de cómo también desde la prensa local no hay más camino que innovar diseñando

programas de acción específicos. Es el caso que aquí se desarrolla a partir del plan de acción que se puso en marcha en Diario de Sevilla entre octubre de 2016 y junio de 2017 y que se ha ido exportando al resto de cabeceras.
\end{abstract}

PALABRAS CLAVE

Ciberperiodismo, Prensa, Redes sociales, Plan de Comunicación, Interacción, Facebook, Twitter, WhatsApp

\section{ABSTRACT}

The interaction of the Press with readers has historically limited itself to publishing a daily selection of their letters to the Editor. With the expansion of social networks, with more strength and transformative impact than the web itself, the newspapers begin to assume the challenge of publishing and managing the content taking advantage of the characteristics of the new media and their potentialities. Companies have been debating between ignoring the new media ecosystem or adapting themselves by simply replicating printed content. However, the multiple crises that have shaken the last sector have forced to activate specific training plans, implement technological developments according to the needs and respond to the demands of users with an inescapable goal of survival. Grupo Joly, a leading journalistic company in Andalusia, is an example of how local and regional Press has to innovate by designing specific action programs. This is the case here developed from the experience of the nine newspapers of the group and the specific action plan that has been launched in the last year in Diario de Sevilla (October 2016-June 2017) as a pilot project exportable to the rest of the newspapers.

\section{KEYWORDS}

CyberJournalism, Press, Social Media, Communication Plan, Interaction, Facebook, Twitter, WhatsApp 


\section{Introducción: de la tormenta perfecta al desafío digital}

Después de doscientos años de historia, la industria periodística -con la prensa como principal baluarte- sigue afrontando a la defensiva todo lo que suponga un cambio en su estatus y un esfuerzo de adaptación. Fueron la radio y la televisión a comienzos y mediados del siglo $X X$, internet irrumpió en los 90 desencadenando la transformación más radical y profunda que ha vivido hasta ahora el sistema de medios y las redes sociales están marcando un convulso presente que ha llegado a poner en cuestión la existencia misma de los medios como intermediarios necesarios entre las audiencias y la realidad, como prescriptores del debate público y como garantes incluso del sistema democrático. Tal es su predominio que hay autores que sitúan ya las redes sociales como el instrumento más potente de difusión de contenidos e, incluso, defienden cómo los propios medios de comunicación se han convertido en redes sociales (Lara, 2008)

Desde la esfera de las empresas, de los grupos mediáticos, el esquema se repite: la primera reacción es obviar y minusvalorar las aportaciones, incluso oportunidades, que puedan conllevar los avances y las innovaciones tecnológicas; la segunda pauta es una asimilación ficticia, de cara a la galería, estar pero sin creer realmente en el valor de lo nuevo; a la tercera parte del doloroso proceso se llega tarde, más por obligación que por convicción, y después de un implacable periodo de ensayo-error con más incertidumbres que certezas.

La "tormenta perfecta" de las múltiples crisis (de la económica y tecnológica a la de confianza y de identidad) y la "rebelión ciudadana" que ha azotado a la prensa en los últimos años ha terminado actuando de revulsivo para que no sólo los grandes grupos mediáticos, también las pequeñas empresas periodísticas, hayan decidido dar el paso de invertir en la transformación del medio (Edo, 2002; Salaverría, 2007; Carrera, 2008): en la 'forma' que significan los soportes y en el 'fondo' que constituyen los tradicionales géneros, el estilo, las narrativas y el lenguaje; en las rutinas mismas del oficio y hasta en la configuración del negocio como pilar ineludible para la pervivencia del medio.

Porque ha sido el golpe del declive del papel abriendo el interrogante específico del futuro de la prensa -de las premoniciones fallidas de Bill Gates a los pronósticos de Philip Meyers pasando por los fatídicos informes sobre el deadline mundial de la desaparición de los periódicos (Ross, 2010)-, pero también de la larga década de crisis económica que estalló en 2008 y que se ha llevado por delante casi cuatrocientos medios (Gómez, 2015) con los mayores índices de paro en la profesión de toda la democracia (APM, 2016), y una caída de la publicidad que las empresas ya dan por irrecuperable pese a los atisbos de recuperación y crecimiento que apuntan los últimos datos macroeconómicos.

Impactos estructurales y coyunturales que se suman a la transformación social y de hábitos de consumo de medios que ha impuesto el Mundo Digital (Negroponte, 1995) y la Galaxia Internet (Castells, 2001) como recogen todos los informes sobre la expansión de las tecnologías y la revolución que están suponiendo los millenials (Ramos-Méndez y OrtegaMohedano, 2017) y, casi lo más preocupante, el derrumbe de la confianza y la credibilidad de los medios rompiendo el pacto no escrito con los lectores que durante decenios ha mantenido vigente la marca y la capacidad de prescripción de los medios tradicionales que ahora ponen en cuestión los llamados "prosumidores" y los propios ciudadanos como partícipes activos de los procesos (García de Torres, 2010).

Realmente, hasta que el negocio no se ha tambaleado poniendo en riesgo la existencia misma del medio no ha habido una reacción seria para afrontar el desafío digital. Mientras el valor de la marca ha sido un salvavidas, un factor de diferenciación y un plus competitivo ante los nuevos medios (Herrero-Solana y Trillo-Domínguez, 2014), no se ha querido escuchar la voz de alerta que lanzaban las audiencias desplazando por completo a los medios tradicionales en su dieta informativa y cuestionando el papel de los grandes grupos frente al periodismo independiente y alternativo (Reig, 2015).

Pero el dilema va más allá de la contraposición entre viejos y nuevos medios. Hablamos de un nuevo ecosistema mediático (Orihuela, 2012) que trastoca por completo los paradigmas que han marcado hasta ahora la comunicación (Orihuela, 2004), que desdibuja las fronteras clásicas entre información, márketing y publicidad conectando cada vez más los campos de la la ficción y la no ficción (Jarvis, 2016) y que tiene en el pujante desarrollo del transmedia storytelling (Jenkins, 2009; Scolari, Jiménez y Guerrero, 2012; Tognazzi, 2012) una de sus vías de exploración más sugerentes y rompedoras. Todo ello, además, con un determinante predominio de lo audiovisual y el entretenimiento derivado de los nuevos hábitos de consumo y orientado a la necesaria reconexión de los medios con las nuevas audiencias (Trillo-Domínguez y Alberich-Pascual, 2017).

Hoy, probablemente sean los 'millenials' quienes mejor simbolicen el papel de marginalidad al que pueden abocar las dinámicas actuales de consumo informativo con la irrupción de fenómenos como los 'influencers' y las crecientes críticas de connivencia entre los grandes medios y el poder político y económico dibujando una oferta informativa con la que ni se identifican ni les 'representa'. El problema es por cuanto supone su desconexión de la estructura mediática en la caída de las cifras de consumo pero lo es, sobre todo, en el medio y largo plazo en tanto que serán estos jóvenes nacidos entre los 80 y el 95 (que ahora tienen entre 21 y 36 años) quienes marcarán las reglas del juego de la nueva industria cuando 
asuman responsabilidades en los propios medios y se sitúen al 'otro lado' de la comunicación corporativa, las relaciones públicas y el márketing.

Sobre todo, si los medios se empeñan en seguir mirando hacia otro lado confiando en recuperar tanto sus posiciones de privilegio en la estructura empresarial periodística como su simbólico papel de cuarto poder sin darse cuenta de que el quinto poder, el de las audiencias, el de la gente, no sólo llegó para quedarse (Ramonet, 2003); llegó para espolear a la adormecida prensa y recordarle que los principios y la ética que justificaron un día su expansión son hoy, en el océano de información, más necesarios que nunca.

Ciertamente, todos los informes sectoriales de los últimos años se presentan como una sonora llamada de alerta para la industria de los medios: la radiografía anual que realiza el Pew Research Center constata, por ejemplo, el imparable crecimiento en el consumo de noticias digitales y el auge de las redes sociales difuminando la brecha con otras plataformas como la televisión y disparando el uso de los dispositivos móviles (Bialkit y Matsa, 2017). Es algo que las investigaciones realizadas por el Reuters Institute de la Universidad de Oxford y la Facultad de Comunicación de Navarra ya ponía de manifiesto en el Digital News Report de 2016 al constatar cómo las plataformas sociales son la primera vía online de acceso a la información, por delante de las webs y de las aplicaciones de los medios, y cómo son los propios periodistas los que marcan la generación de contenidos (AMI, 2017).

En esta misma línea podemos destacar los estudios y trabajos de exploración en el propio sector mediático que realiza el NiemanLab de Harvard y que, en el caso del 2017 que acabamos de cerrar, ya ha sido bautizado como "the year in digital and social media research" a partir de la selección de los diez artículos más reveladores y de mayor impacto publicados en este campo. Tópicos como las nuevas empresas respaldadas por capital riesgo, el auge de la inteligencia artificial en el periodismo, el papel de la marca personal del periodista en el juego mediático y la peligrosa difusión de la desinformación (de la posverdad a las fakenews especialmente en el campo de la comunicación política) determinan las principales tendencias de la industria en un contexto de absoluta preponderancia de los medios sociales (Ordway, 2018).

¿Crisis u oportunidad? Una vez más, los medios se enfrentan al mismo dilema que ha marcado su continua adaptación y transformación a lo largo de la historia. Si atendemos a las tendencias y desafíos del actual sistema de medios, podríamos sostener con similar coherencia cualquiera de las dos partes del interrogante. Sin embargo, si profundizamos en esa idea -cada vez más compartida tanto en el contexto académico como profesional- de que hablamos de una crisis de la empresa, del negocio, de la industria, y no del oficio, de la profesión, del periodismo, podríamos defender que sería hasta un comportamiento suicida por parte de los medios no aprovechar las ventanas de oportunidades que están generando la nuevas tecnologías y el imparable proceso de digitalización.

Justamente en este contexto de oportunidades, nacidas de la dura crisis que ha golpeado a los medios españoles en la última década, se enmarca el proyecto impulsado por Grupo Joly para establecer, desde el periodismo local, un plan de acción y una estrategia eficiente de comunicación en Redes Sociales. Estudios recientes como el realizado sobre El Consumo mediático de adolescentes y jóvenes -en el marco de un ambicioso proyecto de $1+D+i$ en torno a Redes sociales, adolescentes y jóvenes: convergencia de medios y cultura digital- son especialmente reveladores en tanto que desmontan el mito de la falta de interés de las nuevas generaciones por la información y ponen el foco en los cambios de patrones de consumo, la fragmentación de las audiencias y la preponderancia de los social media (García Jiménez, Tur-Viñes y Pastor Ruiz, 2018).

Los primeros resultados del Plan de Acción que avanzamos en este trabajo parten, además, de dos tendencias clave del actual panorama mediático: por un lado, la fortaleza que supone el periodismo local y regional en el saturado y desacreditado mundo globalizado de la (des) información y, por otro, en la constatación de que, con independencia de los soportes y patrones de consumo, hay futuro para los medios de siempre que se han hecho un camino y se han ganado un espacio desde la profesionalidad y el rigor periodístico. Incluso en el caso de los jóvenes como revelan estudios recientes (Digital News Report, 2017) que sitúan la "marca" como un factor distintivo y determinante de acceso a la información.

\section{Metodología}

Unas de las características que han venido definiendo los planes de innovación que han afrontado los grupos periodísticos españoles han sido la prudencia y el conservadurismo: a nivel nacional, las grandes empresas siempre han tenido como referencia los grandes centros de innovación global -Estados Unidos con medios como The New York Times como baluarte y el mundo anglosajón con la $B B C$ o The Guardian a la cabeza- y, en una escala interna, estas mismas dinámicas se ha observado si se analizan los limitados movimientos que han ido desarrollando en las últimas décadas los grupos y pequeñas empresas periodísticas que operan en el contexto local y regional respecto a los dos principales focos de actividad mediática del país, que se concentran en Madrid y Barcelona en tanto que sedes tanto de las grandes corporaciones como de las cabeceras y medios con difusión e impacto nacional.

En este escenario, el reto digital ha venido a justificar los intentos más o menos exitosos que los distintos medios 
han desarrollado con la puesta en marcha de laboratorios de innovación periodística que permitieran afrontar los desafíos del nuevo ecosistema de medios, ensayar nuevos perfiles periodísticos, responder a las nuevas características y exigencias de los públicos y abrir, en definitiva, la profesión a otras áreas pujantes como son las telecomunicaciones, las industrias culturales y del entretenimiento y lo audiovisual.

La apuesta de Grupo Joly, compañía de referencia en Andalucía que justo en 2017 ha celebrado el 150 aniversario de su nacimiento con la fundación en 1887 de Diario de Cádiz -la cabecera decana de la prensa española-, se produjo justo en los primeros meses del pasado año con la puesta en marcha de JolyLAB. Siguiendo un modelo similar al ya implantado y experimentado con éxito por otros medios de posicionamiento e intereses afines como Diario de Navarra, la compañía de la familia Joly ha integrado perfiles diversos de las nueve cabeceras que constituyen el grupo y de áreas complementarias (la propiamente periodística, la digital y la de redes sociales con márketing, informática, negocio y difusión).

Este trabajo recoge las primeras experiencias que se han llevado a cabo en el marco del salto digital $y$, en concreto, presenta los primeros resultados del Plan de Acción diseñado para mejorar los posicionamientos de las diferentes cabeceras en las redes sociales, alcanzar nuevos públicos -especialmente el colectivo de los jóvenes que está absolutamente desenganchado del consumo de periódicos de papel- y explorar nuevas vías de ingresos y de negocio. Se presenta, así, como un valioso estudio de caso en tanto que refleja la apuesta por la innovación y la adaptación mediática de un grupo de referencia en el sector de la prensa española y, desde el periodismo local y regional, líder en el ámbito andaluz.

De cara a sintetizar las primeras experiencias en este campo, se fijan dos tiempos de análisis (octubre de 2016 y junio de 2017) a partir de la implantación de un nuevo gestor para las ediciones digitales de las nueve cabeceras (BitBan) que aporta más información y mejora considerablemente las posibilidades para el desarrollo de contenidos y la incorporación de nuevas estrategias de comunicación que contribuyeran a hacer las webs más interactivas y permitieran reforzar los contenidos audiovisuales y multimedia con primeras experiencias en el campo del periodismo de datos, el periodismo de inmersión o la gamificación.

Asimismo, se completa esta propuesta metodológica con la progresiva exportación de la experiencia de Diario de Sevilla, la implementación de las estrategias de comunicación a todos diarios online de Grupo Joly y la puesta en marcha de un nuevo gestor de redes sociales (DogTrack) que diera mayor autonomía a cada periódico y ayudara a afrontar una gestión más ágil y efectiva de las distintas redes. Un proceso en el que está inmerso tanto el equipo de Digital de Grupo Joly como las redacciones de las nueve cabeceras.

\section{Estrategias periodísticas para la comunicación y publicación en Redes Sociales}

Tomando como punto de partida la experiencia acumulada en las nueve cabeceras de Grupo Joly desde la puesta en marcha de las ediciones digitales con el nuevo siglo, y tomando como proyecto piloto Diario de Sevilla por ser la cabecera que concentra los servicios y equipos comunes de trabajo y que ha tenido un mayor crecimiento y proyección anteriores, se elabora un Plan de Acción en Redes Sociales, se desarrolla un programa de formación en todas las cabeceras y, en base al feedback que se obtiene aprovechando la mayor y más precisa información que el nuevo gestor y las nuevas herramientas de medición nos proporcionan, se van modificando las estrategias y pautas de comunicación tanto en lo referente a las rutinas como a los propios contenidos. Entre otoño de 2016 y la primavera de 2017, ya podemos observar un cambio exponencial en cuanto a flujos y unos indicios tremendamente valiosos sobre el impacto de las noticias.

El siguiente apartado recoge una síntesis de las principales estrategias para la comunicación en Redes Sociales que se ponen en marcha con objeto de ir midiendo su efectividad y resultados -siguiendo el tradicional método del ensayo-error-. En este punto debemos remarcar la fiabilidad y contundencia de los datos cuantitativos obtenidos, si bien todo lo relativo a lo cualitativo, a los temas de apuesta, a los contenidos, entendemos que requerirían de un estudio específico más pormenorizado. Aun así, consideramos que es información relevante en cuanto apunta a tendencias y orienta sobre qué contenidos tienen mayor o menor aceptación entre el público de los periódicos en las redes sociales, con unas características muy diferentes al convencional del papel.

Inicialmente, ya se pone de manifiesto la distancia que hay entre la agenda setting de los medios tradicionales y los contenidos que realmente interesan a los ciudadanos en función del nivel de interacción, de retuiteos, inclusión de comentarios, etc. Los temas políticos y económicos, por ejemplo, apenas suscitan movimiento en las redes sociales frente al gran impacto que tienen los temas educativos $y$ sanitarios, todo lo referente a avances en la investigación, historias curiosas y de entretenimiento... El concepto de lo importante, de lo relevante, difiere claramente si se analizan los datos estadísticos sobre el consumo. No obstante, entendemos que son apuntes iniciales que requerirían un estudio específico más desarrollado que extiende el objeto de este primer trabajo sobre el desafío digital en Grupo Joly.

\subsection{Estrategias de acción en RRSS para la prensa local}

Como punto de partida para el desarrollo del Plan en Redes Sociales de Grupo Joly, se determinan las plataformas susceptibles de explorar para implementar unas estrategias de 
comunicación y publicación concretas por parte de los nueve periódicos y que son: Facebook, Twitter, Google+, Youtube / Vimeo, Instagram, Snapchat, Spotify y WhatsApp / Telegram. No obstante, son Facebook y Twitter por su expansión y perfil periodístico las que concentran las principales iniciativas.

En el caso de Facebook partimos de la siguiente situación general: el $81 \%$ de internautas españoles tienen cuenta activa; cada usuario le dedica de media 90 minutos diarios; el 68\% de los usuarios de Facebook sigue a marcas, pero de éstos menos de la mitad interactúa con ellas; el $40 \%$ de usuarios que sigue a marcas sigue a medios; el 70\% de usuarios accede a través del móvil; los usuarios españoles consultan FB 6,5 veces al día; los contenidos preferidos por el usuario son: fotos $73 \%$, textos 52\%, vídeos 47\%, links 37\%.

En el caso de la comunidad de Diario de Sevilla que, como decimos es el periódico que se utiliza para el proyecto piloto, las características y desafíos son los siguientes: comunidad baja para el perfil del periódico (20.000 'Me gusta' en el momento del inicio del estudio), escasa capacidad para lograr nuevos 'Me gusta', baja interacción de usuarios en los posts, el alto alcance de la portada del papel respecto a gran parte de posts indica que no se genera suficiente interés, dinamización desigual en horas, cadencias y temas, baja atención a la interacción del usuario, lenguaje casi idéntico a los títulos de las noticias, perfil demasiado informativo para una red como Facebook orientada al ocio y el entretenimiento.

Respecto a las características iniciales del tráfico, se observa que se produce un rebote del $80 \%$ (usuario que sale sin navegar), la media de páginas por visita es de 1,61 en septiembre 2016 (el tiempo medio de lectura de 3:52), dos de cada tres usuarios de FB llegan por el móvil pero el móvil presenta ratios de permanencia muy bajas. A partir de aquí, se establecen las siguientes estrategias de publicación, insistiendo en que se trata de un punto de partida para ir revisando, actualizando y mejorando en función de los resultados que se van obteniendo.

En lo referente a la publicación de contenidos:

- Usar lenguaje distendido y que busque pinchar la pieza que se referencia, sin repetir el titular

- Aprovechar las horas de mayor conexión de usuarios (horas pico: 9:00, 18:00 y, sobre todo, 23:00). Prioridad en publicar en esas franjas y una hora antes

- La portada, el primer post del día

- Tema de apertura o tema propio de calado, el segundo

- Repartir por la mañana los principales temas de Local

- Entre el mediodía y el pico de la tarde posts con informaciones del tipo Vivir, curiosidades o títulos que sugieran interés

- Último tramo: piezas para leer, entrevistas, reportajes...

- Breaking news: muy concretasy de suficiente calado

- No menos de 10 mensajes por día. Preferible $<20$

- Programar siempre salvo urgentes y siempre desde FB (usar herramientas externas está penalizado)

- Buscar mayoría de temas con interés no informativo. Virales y vídeos por la tarde

- Titulares que inviten a hacer click. Nunca repetir título. Editar título/subtítulo del enlace

Sobre los contenidos gráficos:

- Posibilidad de usar/compartirvídeos de terceros (viral)

- Cambiar la foto de cabecera a diario si es posible

- Incluir el logo del periódico en los elementos gráficos

- Galerías de fotos: al menos una diaria: especial énfasis en eventos deportivos, cofrades, de moda y culturales

- Realizar algún gif semanaly postear infografías

En lo referente a Twitter, la situación general que se toma como referencia dibuja el siguiente escenario: el $43 \%$ de internautas españoles tienen cuenta activa (otro $22 \%$ tiene perfil inactivo o lo cerró), Twitter se ha estancado en penetración y en uso (es la red social favorita del $7 \%$ de internautas, WhatsApp lo es del 45\%, Facebook 28\% y YouTube 9\%), el 60\% de usuarios sigue a marcas (de ellos, $43 \%$ interactúa), los medios son las marcas más seguidas (44\%), la posibilidad de acceder en tiempo real a las tendencias permite buscar impacto en grupos de usuarios a los que no llegaríamos, su acceso local permite ver temas de interés para nuestro público, contenido preferido por el usuario: fotos 62\%, textos 49\%, links 40\%, vídeos 37\%

Sobre la comunidad de Diario de Sevilla podemos sintetizar lo siguiente: se parte de una comunidad mediana para el perfil del diario (130.000 al inicio del estudio), el bajo índice de retuits indica que no se genera suficiente interés en las publicaciones, perfil claramente informativo (Twitter es versátil), el número de impresiones de tuits ronda el millón y medio al mes y las menciones superan las 2.300 al mes como tendencia general en los primeros nueve meses de 2016, dinamización desigual en horas, cadencias y temas, baja atención a la interacción del usuario y el lenguaje casi idéntico a los títulos de las noticias.

Se observa que las fotos multiplican el impacto de los tuits, buena capacidad para lograr nuevos seguidores por alto grado de conocimiento de la marca en su área, baja interacción de 
usuarios en los posts, que la redacción retuitea poco las publicaciones en sus perfiles personales y tampoco recibe retuits. Respecto al tráfico, las horas de mayor actividad: 9:00 (sobre todo), 13:00, 18:00 y 22-23:00, el mayor impacto de links suele venir de tuits de otros, twitter supone $25 \%$ o máximo 30\% del total social, la mitad de tráfico que FB con seis veces más usuarios, hay un rebote del $75 \%$ y la media de páginas por visita es de 1,83; el tiempo medio de lectura es de 4:15. Estos datos corresponden a septiembre de 2016.

Partiendo de esta radiografía y de las limitaciones observadas, se plantea una serie de estrategias para que puedan seguir tanto los profesionales del equipo específico de Digital y Redes Sociales como la totalidad de la plantilla de redactores de los diarios:

- Aprovechar las horas de mayor conexión de usuarios

- Usar dos hashtags (genéricos) por mensaje

- $\quad$ Prioridad en publicar en las franjas 9:00, 13:00, 18:00 y 22:00-23:00 sin olvidar que los usuarios no son los mismos ni están siempre. Muro de orden cronológico.

- La portada, el primer post del día

- Tema de apertura o tema propio de calado, el segundo

- Repartir durante el primer tramo de la mañana los principales temas de Local, Provincia, Deportes y Cultura. Ocasionalmentealgún tema de sección común

- Alternar en el segundo tramo matinal (12:00-14:00) artículos de opinión, temas secundarios de las secciones mencionadas y noticias de actualización del día.

- Aprovechar el pico de 13:00h para el tema principal de la mañana, galería, infografía o petición de participación

- Alternar por la tarde mensajes sobre temas del día con temas interesantes que no se hayan sacado. Galerías

- Último tramo: piezas para leer, entrevistas, reportajes, análisis, fondo y republicar un tema propio de interés

- Breaking news: abundantes y con posibilidad de seguimientoy actualización

- Destacar a mediodía y/o por la noche un tema que haya generado una notable repercusión y/o audiencia

- Combinar noticias con temas de interés no informativo

- Virales indistintamente pero mejor por la tarde

- No menos de 10 mensajes por día. Sin límite fijado

- Recomendable usar acortador para seguimiento y para hacer más sencillo que ese link se comparta
Respecto a los elementos gráficos:

- Si una información va sin foto, acompañar con logo del diario

- Posibilidad de incluir vídeos aunque no sean del Grupo

- Cambiar la foto de cabecera a diario si es posible

- Incluir el logo del periódico en los elementos gráficos

- Galerías de fotos: al menos una diaria: especial énfasis en eventos deportivos, cofrades, de moda y culturales

- Realizar algún gif semanaly usar banco de gifs (giphy)

- Tuitear infografías enlazando a la pieza donde estén

- Crear plantilla para imagen de articulistas

Por último, como consideraciones mínimas iniciales respecto al resto de redes sociales, se aportan también unas indicaciones básicas y estratégicas de cara a reforzar las de uso más mayoritario:

- Aprovechar el empeño de Google en el uso de Google+ con un uso mínimo para no ser penalizado

- Utilizar Instagram, Spotify y VuTube como refuerzo de marca con la posibilidad de aprovechar lo que se genere en ellas para otras redes, particularmenteen Facebook

- Explorar Snapchat y la posibilidad de crear suscripciones de contenido en WhatsApp y Telegram

\subsection{Análisis de resultados del Plan de Acción aplicado en Diario de Sevilla}

Aumentar el tráfico social de manera significativa y mejorar la presencia de nuestras marcas en redes sociales (O'Connor, 2009), acentuada por una comunidad en Facebook claramente insuficiente, contemplaba varias situaciones: el cambio de web afrontado por todas las cabeceras de Grupo Joly a principios de noviembre de 2016 permitía, por fin, compartir informaciones de manera simple y eficaz, así que esperar un cierto crecimiento natural de esta procedencia de usuarios parecía lógico. Al tiempo, se sistematizaron acciones concretas, se midieron y se observaron diversas peculiaridades que, sin ser aplicables a todas las cabeceras de la empresa, sí dejaban perfectamente claro que todo lo que funcionaba en la web no tenía por qué obtener el mismo impacto en redes y que ciertos temas recibían una mejor acogida que otros tradicionalmente muy leídos en la página de las cabeceras.

Como punto de arranque, se consideró a Diario de Sevilla la cabecera desde la que ordenar y pautar un trabajo de este tipo, algo que por la merma de recursos no se había acometido con anterioridad. Se presentó un plan de acción global 
que incluía la mayoría de las plataformas actuales, pero para poder optimizar el resultado e intentar reflotar la dimensión de la comunidad (especialmente) en Facebook se aplazaron algunas para centrar los esfuerzos en las dos más comunes y, en menor medida, en Instagram.

En octubre de 2016, la cuenta no llegaba a 20.000 usuarios, un dato demoledor para un periódico del calado de Diario de Sevilla. No había plan, había vacíos amplios, el fin de semana no se atendía de forma adecuada y no se seleccionaban intencionadamente los temas ni los copys. Era una acción automática de la que no se sacaban conclusiones ni se corregían detalles. En Twitter ocurría otro tanto, hasta el punto de estar ambas cuentas sincronizadas por la imposibilidad de alimentarlas debidamente por separado, pero la comunidad sí crecía de manera muy considerable, al nivel lógico de su marca y, en ese momento, marcaba 130.000 seguidores, por los 140.000 de Abc de Sevilla y 105.000 de El Correo de Andalucía, sus tradicionales competidores. Para obtener una imagen nítida del gap existente entre las redes del periódico, Abc contaba con el mismo número de seguidores en ambas redes. Y lo hacía por dos motivos: sistematización y campañas de publicidad en Facebook.

Con la comunidad existente en ese momento, se observa que los tres picos de usuarios en Facebook corresponden a las 9:00, las 18:00 y las 23:00. El fin de semana, al contrario que el tráfico de la web, la actividad en redes mantenía su nivel incluso el sábado, el día tradicionalmente de menos páginas vistas de toda la semana.

Facebook suponía, y supone, un mínimo del 65\% del tráfico social total, con picos y días en los que supera el $70 \%$. El resto es básicamente de Twitter, con una escasa llegada de tráfico desde otras plataformas. Ya ahí se observaba que la procedencia mayoritaria era el Smartphone (2 de cada 3 usuarios), algo muy a valorar puesto que hasta ese momento no era posible disponer de una versión optimizada para el móvil.

Con la convicción de que con el tiempo debería modificarse, se ejecuta un plan de posteado que, junto a una mayor facilidad del usuario para compartir, da como resultado un aumento del tráfico social desde el 9\% de octubre de 2016 al 20\% de abril-mayo de 2017. Dicho plan intenta cubrir todas las franjas horarias de manera ordenada y diferenciada, seleccionando temas y copys y publicando historias de manera independiente e incluso excluyente respecto a Twitter.

De entrada, se procura utilizar un lenguaje relajado y comprensible, con un mayor detenimiento en la elaboración de los copys de Facebook, incluyendo emoticonos, al poder ser los textos explicativos más amplios y ser capaces de producir mucha mayor interacción.

A nivel formal, se establece una media de post diarios de 15, normalmente separados por un lapso de entre 45 y 70 minu- tos cada uno, puesto que la dimensión de nuestra comunidad invitaba a no sobrecargar la acción con posts muy cercanos en el tiempo, habida cuenta de que Facebook no presenta las publicaciones a los usuarios de manera cronológica sino añadiendo otros parámetros como el grado de interacción con quien publica o la relevancia que le otorgan a esa publicación otros usuarios. Del mismo modo, se empieza a editar el texto del post de Facebook diferenciándolo del título que arrastra el link, de manera que complemente la historia, la explique o incite a conocer más sobre la misma.

En cuanto al contenido, prácticamente todo se programa desde la propia plataforma de Facebook, salvo que se publique algo directamente por necesidades del momento; se comienza el día con la portada de la edición impresa. A continuación, durante la mañana, se desglosan los temas locales principales y, al mediodía, se da paso a algún tema ya de menor calado, propio de secciones como Vivir en Sevilla. La tarde y la noche normalmente se desarrollan con temas de cultura, entrevistas, curiosidades y algún tema potente de local que haya podido suceder en este plazo.

Breaking news sólo aparecen en casos muy concretos y deben ser de un calado que, además de considerarse suficiente, puedan obtener repercusión entre los usuarios. Los temas informativos no suelen ser los de más impacto de Facebook, y en particular los deportes no han funcionado. Siempre están entre los más leídos de la web pero la abundancia de fuentes y la capacidad que tienen medios nativos, foros, páginas y usuarios particulares de referenciar nuestro contenido hacen que difícilmente nos adelantemos por esta vía.

El vídeo ha obtenido un peso muy notable en toda esta planificación, puesto que al ser temas agradables de ver en general y de un marcado carácter local no eran tan fáciles de encontrar en otros portales y plataformas, con lo que el nivel de reproducciones e interacciones ha sido en algunos casos sobresaliente.

Tráfico al margen, el resultado de establecer pautas concretas, realizar seguimientos y seleccionar adecuadamente los temas provocó que en los seis meses siguientes a su implantación la comunidad en Facebook creciera un 50\%. Diez mil usuarios en seis meses no parece gran cosa, pero teniendo en cuenta que suponían la mitad de los que había antes puede considerarse un paso muy notable para ir situando a la marca más cerca del lugar que le corresponde. Más aún, la observación de páginas de competidores directos y líderes en nuestro ámbito ha ofrecido tasas de crecimiento semanal que habitualmente doblaban a nuestros competidores siempre que éstos no realizaran campañas de publicidad en Facebook.

La forma en la que se han compartido los posts del periódico se ha transformado de manera muy notable y las estadísticas internas que proporciona Facebook ofrecen un dibujo mucho más optimista y completo que en el momento del comienzo del 
plan. En octubre de 2016, los posts más compartidos alcanzaban las 50 veces y acabando la primavera de 2017 raro era el día en el que un post no superaba las cien veces, llegándose a mil de manera orgánica con la historia de terror vivida por una mujer asesinada por su ex marido a finales de junio.

Twitter, sin entrar es si será una "moda pasajera" como plantean autores como Negroponte (2010), ha recibido un trato más tibio en la forma de presentación de los temas. Se han incluido aquí las piezas de opinión, que normalmente no se publican en Facebook salvo alguna tribuna de particular interés o viñetas de Miki y Duarte muy atractivas. La diferenciación con Facebook es tal que, por ejemplo, los temas de deportes en Twitter sí funcionan de manera notable y las noticias de última hora son abundantes.

Como en Facebook, se decidió comenzar con la portada, y a continuación los principales temas locales, añadiéndose aquí temas de gran calado de fuera de la provincia por la necesidad de rellenar un espacio mucho mayor. Se comenzó con tres tuits por hora separados a intervalos de 20 minutos pero siempre que es posible se ha ampliado a cuatro, programados y con un intervalo de 15 minutos, sin menoscabo de lanzar temas de breaking news intercalados entre los ya previstos o modificando la programación de alguno de ellos.

En octubre se publicaron 317 mensajes (diez al día) para 1,58 millones de impresiones, 2.200 menciones y casi 3.500 nuevos seguidores. En junio de 2017 los mensajes pasaron a 1.150 y las impresiones superaron las cinco millones, con 5.300 menciones y 2.200 nuevos seguidores. En octubre los mensajes más vistos contabilizaban entre 5 y 10.000 impresiones, superando las 20.000 en junio. El crecimiento de la cuenta ha estado por debajo de los 25.000 seguidores en este período para un total de más de 152.000, por los algo menos de 130.000 de octubre.

La actividad en Twitter sigue mostrando una capacidad muy inferior para desviar tráfico y un nivel de retuits bastante bajo para el tamaño de la comunidad disponible, a pesar de lo cual el crecimiento en tráfico desde Twitter ha evolucionado al mismo ritmo que el de Facebook, pues la proporción en porcentaje apenas ha variado a pesar de haberse doblado el tráfico social. Al contrario que Facebook, el uso no es tan intensivo, la cronología online hace que en muchas situaciones los mensajes se pierdan o no se pueda conseguir la misma rapidez de otras plataformas y usuarios y las historias de fondo tienen un impacto muy inferior que en Facebook porque el usuario normalmente escanea su timeline en busca de titulares, por lo cual el empleo de fotos es esencial y hasta el momento del cambio de web no se hacía de manera automática.

Las horas de mayor actividad observada son similares a Facebook, aunque en este caso se añade la última hora antes del almuerzo (de 13 a 14 horas), pero el tráfico que se consigue atraer no alcanza ni de lejos las cotas de Facebook. De hecho, en el mejor escenario está en la mitad, llegando a estar en un tercio cuando Facebook ha conseguido colocarse por encima del $70 \%$, a pesar de contar con cinco veces más seguidores.

\section{Conclusiones y futuras líneas de trabajo}

Pese a las limitaciones de los actuales sistemas de análisis en el entorno web, la valoración de todos los datos sobre la evolución del tráfico e interacción con la web de Diario de Sevilla a partir de la mejor y más sistemática publicación en las Redes Sociales revela una importantes toma de conciencia inicial: la aplicación de una mínima estrategia de publicación tiene resultados, es un error estar por estar, sobre todo si tenemos en cuenta el esfuerzo que supone y la poca rentabilidad final que se logra.

En la práctica, es una manera aplicada de llevar a cabo los planteamientos académicos en torno al periodismo transmedia (Scolari, 2013): no mover contenidos sin más en diferentes soportes, sino contar historias de forma diferente aprovechando y adaptando el contenido a los diferentes medios atendiendo a sus especificidades. No se puede escribir igual para papel que para web y tampoco escribir ni publicar con las mismas estrategias y tiempos en las diferentes redes sociales. Lo que interesa en el papel no tiene por qué tener un reflejo similar en las audiencias potenciales de las Redes Sociales.

Las acciones de social media son dinámicas, están vivas y deben ser revisadas en función de cómo se están comportando entre nuestra comunidad, y qué capacidad tienen los temas elegidos de generar el suficiente interés para ser compartidos por quienes siguen al medio y, a su vez, entre los que se mantienen al margen.

Todo plan debe dejar un espacio amplio para adaptarse a la casuística que representa un volumen de usuarios tan amplio. Cuestiones como, por ejemplo, cuidar los copys y el aspecto de los post resulta esencial para que, una vez que se ha publicado un tema capaz de generar interés y respuesta, resulte atractivo para lograr mayor recorrido. Los elementos audiovisuales adquieren un papel cada vez más relevante, tanto las imágenes para acompañar los temas como los vídeos subidos independientemente: aunque no enlacen al medio generan un engagement suficiente para que compense ampliamente su publicación sin que haya retorno de tráfico.

Pese a las limitaciones con que se afronta el desafío digital desde el periodismo local, en empresas sin los recursos de las grandes corporaciones mediáticas, entendemos que el caso de Grupo Joly viene a demostrar la rentabilidad de la innovación periodística -más allá de modas-y de la necesidad, si queremos reforzar el valor de las marcas, de construir un espacio dentro del nuevo ecosistema de medios sumándonos al sistema de reglas que imponen los cada vez más exigentes 
y participativos públicos. La prensa local y regional no sólo no puede estar ajena a los procesos de transformación, sino que puede asumir incluso el liderazgo marcando el camino y aprovechando sus ventajas de cercanía, empatía e identificación con los potenciales lectores y usuarios.

En este contexto, los resultados de la experiencia que se recoge en este trabajo han llevado a Grupo Joly a reforzar su apuesta por los contenidos digitales y las estrategias de comunicación en Redes Sociales. Desde noviembre de 2016, con un cambio de responsabilidad en el equipo ${ }^{2}$, se ha intensificado el proceso de transformación digital en el grupo, empezando por la inversión en un nuevo gestor de contenidos (herramienta BitBan), optimizando algunos procesos técnicos e iniciando una integración de las redacciones (papel y digital). La idea es que toda la corporación se contagie de una cultura digital necesaria para la transformación como medio de comunicación en un momento en el que las ediciones en papel van cayendo y el auge está en las digitales; trabajar de una manera coordinada en los nueve periódicos y suplir la necesidad de una mayor inversión y recursos uniendo las plantillas y formando un proyecto único y fuerte.

Siguiendo esta filosofía, y con la puesta en marcha del proceso antes descrito, se ha permitido estabilizar el tráfico en algunos casos y, en otros, registrar destacados aumentos. La navegación es más rápida, más limpia y clara y se ha empezado a apostar por contenidos propios, diferentes a las de las ediciones digitales, y a aplicar un mayor-mejor criterio editorial en las webs. Una vez superada la fase de despegue, el reto sigue estando en las redes sociales, abordándolas con concepto de grupo. Desde septiembre de 2017 se ha diseñado una estrategia concreta: analizar los momentos de mayor tráfico, los contenidos de más éxito en cada cabecera y trazar una forma de actuar común. A partir de aquí se ha empezado a elaborar un plan editorial, otro de gestión de crisis y se está explorando cómo mejorar la capacidad de interacción con el lector.

Una vez que concluya este chequeo a todas las redes y se defina la estrategia, lo siguiente será invertir en la generación de contenidos específicos para redes que permitan aumentar el tráfico y mantengan o refuercen la credibilidad del medio, lo que finalmente sostiene el volumen actual de lectores. De entrada, ya han identificado las principales apuestas: vídeo y material interactivo enfocado siempre a lo local, el distintivo del grupo y fuerza para competir dentro de un sector como la prensa tan dependiente de su prestigio y reputación.

En breve, también se pondrán en marcha nuevos canales para interactuar con el lector. De forma inminente se activará un piloto con una lista de WhatsApp que, con el enfoque de newletters, permitirá enviar a quienes se suscriban a esa lista un resumen, una vez o dos al día, con las noticias locales más importantes del día. También se ha previsto reactivar las cuentas de Instagram, dando más protagonismo al contenido gráfico que generamos a diario (todo ello acorde a la propia evolución sobre el uso de redes sociales que se está produciendo en los últimos años y que ya recogen estudios como el Digital News Report de 2017).

A nivel de investigación, y volviendo al estudio de caso que aquí se presenta, todo el trabajo que ahora se afronta permitirá analizar la propia evolución de los diarios tanto en la web como en las Redes Sociales, extraer comparativas y obtener también un sólido corpus estadístico que poder comparar con el trabajo que se está realizando en otros medios y grupos de comunicación.

\section{Referencias}

APM (2016). Informe de la Profesión Periodística. Recuperado de http://www.apmadrid.es/publicaciones/informe-anual-de-la-profesion

AMI (2017). La información en la Era Digital: el periodista como principal creador de contenidos. Asociación de Medios de Comunicación. Recuperado de https://www.ami.info/periodista-principal-creador-de-contenidos.html

Bialik, K., y Matsa, K. E. (2017). Key trends in social and digital news media. Pew Research Center. Recuperado de http://www.pewresearch.org/fact-tank/2017/10/04/key-trends-in-social-and-digitalnews-media

Carrera, P. (2008). Periodismo en la era de internet. Madrid: Ariel.

Castells, M. (2001). La Galaxia Internet. Reflexiones sobre internet, empresa y sociedad. Madrid: Areté.

Edo, C. (2002). Del papel a la pantalla. La prensa en Internet. Sevilla: Comunicación Social Ediciones y Publicaciones.

García de Torres, E. (2010). Contenido generado por el usuario: aproximación al estado de la cuestión. El Profesional de la Información, 19(6), 585-594.

García Jiménez, A., Tur-Viñes, V., y Pastor Ruiz, Y. (2018). Consumo mediático de adolescentes y jóvenes. Noticias, contenidos audiovisuales y medición de audiencias. Icono 14, 16(1), 22-46.

Gómez, R. (2015). La crisis ha provocado el cierre de 375 medios de comunicación. El País. Recuperado de http://politica.elpais.com/politica/2015/12/16/actualidad/1450287352_341538.html

Herrero-Solana, V., y Trillo-Domínguez, M. (2014). Twitter Brand Directors: el efecto marca en las redes sociales de los directores de medios españoles. Estudios sobre el Mensaje Periodístico, 20 (1), 131-146.

Jarvis, J. (2015). El fin de los medios de comunicación de masas. ¿Cómo serán las noticias del futuro? Barcelona: Gestión 2000.

Jenkins, H. (2009). Fans, blogueros y videojuegos. La cultura de la colaboración. Barcelona: Paidós.

Lara, T. (2008). La nueva esfera pública. Los medios de comunicación como redes. Telos, (76). Recuperado de https://telos.fundaciontelefonica.com/telos/articulocuaderno.asp@idarticulo $=9 \& \mathrm{rrev}=76 . \mathrm{htm}$

Negroponte, N. (1995). Being Digital. New York: Knopf Inc.

Negroponte, N. (2010). Twitter es una moda pasajera. El País. Recuperado de https://elpais.com/tecnologia/2010/11/04/actualidad/1288864868_850215.html 
O'Connor, R. (2009, 20 January). Facebook and Twitter Are Reshaping Journalism As We Know It. RoryOConnor.org. Recuperado de http:// www.alternet.org/mediaculture/121211/facebook_and_twitter_are_ reshaping_journalism_as_we_know_it

Ordway, D. M. (2018). Cross-examining the network: The year in digital and social media research. NiemanLab Harvard Foundation. Recuperado de http://www.niemanlab.org/2018/01/cross-examining-the-network-the-year-in-digital-and-social-media-research/

Orihuela, J. L. (2004). eCommunication: the 10 paradigms of media in the digital age. En: Salaverría, Ramón y Sádaba, Charo (Eds.), Towards New Media Paradigms: Content, Producers, Organizations and Audiences, Pamplona: Ediciones Eunate.

Orihuela, J. L. (2012). 80 claves sobre el futuro del periodismo. Madrid: Anaya Ediciones.

Salaverría, R. (2007). Los diarios frente al reto digital. Chasqui. Revista Latinoamericana de Comunicación. (97), 4-10. doi:10.16921/ chasqui.v0i97.402

Ramos-Méndez, D., y Ortega-Mohedano, F. (2017). La revolución de los hábitos de uso y consumo de vídeo en teléfonos inteligentes entre usuarios Millenials, la encrucijada revelada. Revista Latina de Comunicación Social, (72), 704-718.

Ramonet, I. (2003). El quinto poder. Le monde diplomatique. Recuperado de http://monde-diplomatique.es/2003/10/ramonet.html

Reig, R. (2015). Crisis del sistema, crisis del periodismo. Contexto estructural y deseos de cambio. Barcelona: Gedisa Editorial.

Ross, D. (2010). Newspaper extinction deadline. Fundación Future Exploration Network. Recuperado de https://rossdawson.com/ frameworks/newspaper-extinction-timeline

Scolari, C. (2013). Narrativas transmedias. Cuando todos los medios cuentan. Barcelona: Deusto.

Scolari, C., Jiménez, M., y Guerrero, M. (2012). Transmedia Storytelling in Spain: four fictions searching for their cross-media destiny. Communication \& Society, 25(1), 137-164.

Tognazzi, A. (2012). Las transformaciones de los contenidos audiovisuales y la influencia de los dispositivos móviles en el nuevo escenario transmedia. Anàlisi: Quaderns de comunicació i cultura, [Monogràfic: Audiovisual 2.0] ,81-95.

Trillo-Domínguez, M., y Alberich-Pascual, J. (2017). Deconstrucción de los géneros periodísticos y nuevos medios: de la pirámide invertida al cubo de Rubik. El Profesional de la Información, 26(6), 1091-1099.

\section{Notas al final de página}

1. Los datos concretos que se recogen corresponden al periodo de análisis. Las estadísticas han ido evolucionando y reflejan ya un crecimiento muy destacado en todos los parámetros (serán objeto de estudios posteriores).
2. María José Guzmán se puso al frente del proyecto digital de Grupo Joly en noviembre de 2016 como redactora jefe responsable de los Contenidos Digitales. La situación actual y estrategias a corto y medio plazo que se avanzan en este apartado final como Futuras Líneas de Trabajo son una aportación directa de ella para completar este primer análisis sobre el Plan de Acción en Redes Sociales de Grupo Joly.

\section{CV}

Magdalena Trillo-Domínguez. Compagina la docencia como profesora de Comunicación Periodística y Sistema Mediático en la Universidad de Granada con su actividad profesional como directora del periódico Granada Hoy, una de las nueve cabeceras de Grupo Joly (compañía editorial de referencia en la prensa andaluza). Doctora en Comunicación por la UGR con una tesis que por primera vez aplicaba en España avanzadas técnicas de análisis cibermétrico a la prensa, forma parte del grupo de investigación Nar-trans y es integrante del Laboratorio de Innovación que ha creado Grupo Joly para afrontar el desafío digital. Sus principales áreas de trabajo son géneros y narrativas en los nuevos medios y estrategias de innovación periodística enfocadas al campo transmedia. Colaboradora habitual de los espacios de análisis y debate de la RTVA.

Jesús Ollero. Es periodista y profesor universitario. Miembro de la redacción fundacional de Diario de Sevilla (1999), pasó a coordinar la web del periódico a finales de 2006 y los portales de todas las cabeceras de Grupo Joly entre 2010 y finales de 2016. Dirigió un equipo de trabajo galardonado con el Premio Andalucía de Periodismo en 2014. En los últimos años ha impartido clase en castellano y en inglés de Multimedia y de Innovación Periodística en el centro universitario EUSA, adscrito a la Universidad de Sevilla. Actualmente es el coordinador de comunicación digital de la Oficina del Portavoz del Gobierno de la Junta de Andalucía. 